\title{
Cysteamine in Maturation Medium Enhances Nuclear Maturation and Fertilization Rate of Sheep Oocytes In Vitro
}

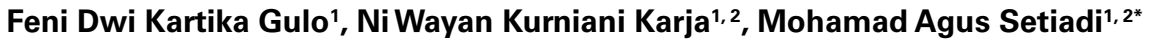 \\ 'Study Program of Reproductive Biology, Graduate School, IPB University, Bogor, Indonesia \\ ${ }^{2}$ Department of Veterinary Clinic, Reproduction and Pathology, Faculty of Veterinary Medicine, IPB University, Bogor, Indonesia
}

\section{ARTICLE INFO}

Article history:

Received March 22, 2019

Received in revised form September 15, 2020

Accepted September 20, 2020

\section{KEYWORDS:}

cysteamine,

in vitro,

nuclear maturation,

fertilization,

sheep oocytes

\begin{abstract}
Low nuclear maturation and fertilization rate is one obstacle in the in vitro embryo production which decrease embryo yield. This problem is presumable related with high production of reactive oxygen species (ROS) during maturation process. Glutathione (GSH) as an antioxidant is well known to overcome effect of ROS production. GSH synthesis in the cytosol part of the oocyte cytoplasm is influenced by cysteine availability. It is therefore, this research was conducted to evaluate the ability of cysteamine to provide cysteine availability as GSH precursor on the nuclear maturation and fertilization rate of sheep oocytes. Results of this experiment revealed additional cysteamine at $150 \mu \mathrm{m}$ and $200 \mu \mathrm{m}$ could significantly improve nuclear maturation rate. On the other side, although additional of cysteamine at $50 \mu \mathrm{m}$ could not improve nuclear maturation rate, however $50 \mu \mathrm{m}$ cysteamine in the maturation medium could significantly improve the fertilization rate. Based on those experiment results, it seems that the additional cysteamine might be improve not only GSH availability but also the oocyte quality which characterized the ability of pronuclear formation. This finding strongly suggested that additional cysteamine in the maturation medium could improve nuclear maturation and fertilization rate of sheep oocytes.
\end{abstract}

\section{Introduction}

In vitro embryo production (IVEP) is currently one of the most important biotechnology in agriculture and biomedical research. IVEP have been widely used to upgrade genetic performance, overcome infertility, produce transgenic and cloned animals, and provide a source of sexed embryos especially for the conservation of endangered species (El-Aziz et al. 2016). According to Regulation of Indonesian Minister of Environment and Forestry, there are still 137 protected species of mammals and 5 of them are family Cervidae (MENLHK 2018). In order to save endangered species, it is required to introduce an advanced of reproductive technology. Since a limited sample number from endangered species, it is usually used the closed related domestic animal phylogenetically for the research purpose as model for endangered species, i.e. sheep or goat for family Cervidae (Arregui et al. 2008).

It is well known that one factor of the success of IVEP is influenced by oocyte quality. To achieve oocyte competence for embryo production, the

\footnotetext{
* Corresponding Author

E-mail Address: setiadi03@yahoo.com
}

oocyte requires a certain stage of nuclear maturation. Oocyte quality during maturation process is strongly influenced by the balance between reactive oxygen species (ROS) levels and antioxidants within in vitro maturation (IVM) medium (Khazaei and Aghaz 2017). Abnormal ROS levels might facilitate various pathological processes, such as mitochondrial dysfunction, apoptosis, decreased fertilization rate, poor embryo quality, and abnormalities in offspring (Lord and Aitken 2013). Many researchers reported the beneficial effect of antioxidant supplementation either in maturation medium (Sadeesh et al. 2014; Kang et al. 2016; Sovernigo et al. 2017) or in culture embryo (Hosseini et al. 2009; Karasahin and Arikan 2015) for developmental oocyte competence. Glutathione (GSH) is very popular antioxidant added in the culture system.

GSH is an intracellular thiol molecule and a potent antioxidant that plays an important role in the defense against ROS (Dominko and Dikic 2018) and pronuclear formation (Nugroho et al. 2017; Shirazi et al. 2018). GSH biosynthesis depends on cysteine availability in the IVM medium (Lu 2013). However, Cysteine is susceptible to be auto-oxidized to cystine, which causes of cysteine insufficient to decrease of GSH synthesis 
(De Matos and Furnus 2000). It is well reported that cysteamine has the capability to reduce cystine to cysteine, therefore increase of GSH synthesis during oocyte maturation (De Matos et al. 1995; Gasparrini et al. 2003; Zhou et al. 2008), thus oocyte competence can be improved. Based on those mechanisms, research on addition cysteamine into the maturation medium has been conducted to observe improvement on nuclear maturation competence and the ability of sheep oocytes to be fertilized which characterized by pronuclear formation.

\section{Materials and Methods}

\subsection{Oocyte Collection}

The ovaries were obtained from a slaughterhouse, and rinsed with $0.9 \%$ of $\mathrm{NaCl}$ supplemented with 0.1 $\mathrm{mg} / \mathrm{ml}$ of streptomycin (Sigma-Aldrich) and $100 \mathrm{mg} /$ $\mathrm{ml}$ of penicillin (Sigma-Aldrich, St. Louis, MO, USA), and transported to the laboratory at $34-36^{\circ} \mathrm{C}$ less than 5 hours. Oocytes were then collected by slicing using a scalpel in a sterile petri dish containing $2 \mathrm{ml}$ of phosphate buffered saline (PBS) supplemented with $0.3 \%$ of bovine serum albumin (BSA) (Sigma-Aldrich. Inc, P-4687), $100 \mathrm{IU} / \mathrm{ml}$ of penicillin, and $0.1 \mathrm{mg} / \mathrm{ml}$ of streptomycin. Collected oocytes were evaluated and selected under a stereo microscope (Olympus IX, Japan). Only oocytes with compact cumulus cells and homogeneous cytoplasm were used for the maturation process.

\subsection{In Vitro Maturation (IVM)}

The method of oocyte maturation in this research refers to the research conducted by Setiadi and Karja (2013) with few modifications. Oocytes were matured in the drop of $100 \mu \mathrm{l}$ maturation medium containing 10-20 oocytes and covered by mineral oil (Sigma, USA). The basic medium used for maturation was medium 199 (Sigma-Aldrich. Inc., M4530) supplemented with $0.3 \%$ of bovine serum albumin (BSA) (Sigma, USA), 10 $\mathrm{IU} / \mathrm{ml}$ of follicle stimulating hormone (FSH) (Vetoquinol N.- A inc, Lavaltrie, Quebec, Canada), $10 \mathrm{IU} / \mathrm{ml}$ of human chorionic gonadotrophin (hCG) (Kyoritsu Seiyaku, Tokyo, Japan) and $50 \mu \mathrm{g} / \mathrm{ml}$ of gentamycin (Sigma, USA). In this research, oocytes were matured in a basic medium supplemented with multilevel cysteamine (Aldrich-M9768) concentrations; i.e. 0 (control), 50, 100,150 , and $200 \mu \mathrm{m}$, then were incubated in a $5 \%$ $\mathrm{CO} 2$ in air at $38.5^{\circ} \mathrm{C}$ for 24 hours.

\subsection{Evaluation of Maturation Rate}

Assessment of oocyte nuclear maturation ability was done based on the percentage of oocyte reached the metaphase II (MII) stage. After the maturation process, oocytes were denuded of the cumulus cells by repeated pipetting in PBS containing $0.25 \%$ hyaluronidase (Sigma, USA). Denuded oocytes were washed and placed on a drop of PBS + BSA $0.3 \%$ on a slide and overlaid with a coverslip supported by Vaseline stripes: paraffin mixture (9:1). Oocytes were fixed in ethanol absolute and acetic acid solutions (3:1) for 48-72 hours. After that, the oocytes were stained by $2 \%$ aceto-orcein for 2-3 minutes and rinsed with $25 \%$ acetic acid. Observation of nuclear maturation stage was performed by using a phase-contrast microscope (Olympus IX, Japan).

\subsection{In Vitro Fertilization (IVF)}

Oocyte collection and maturation was carried out as in the research (2.1). In vitro fertilization was conducted using frozen sheep semen taken from the Center for Artificial Insemination, Lembang, Bandung. The frozen semen was thawed in water bath at $37^{\circ} \mathrm{C}$ for 30 seconds. The semen was collected in a $15 \mathrm{ml}$ sterile centrifuge tube (Corning Centristar ${ }^{\circledR}$ ) containing 4 $\mathrm{ml}$ of fertilization medium (Suzuki et al. 2000), then was centrifuged at $1500 \mathrm{rpm}, 28^{\circ} \mathrm{C}$ for 5 minutes. After centrifugation, a portion of the sperm pellet was diluted with a fertilization medium to reach the final concentration of $5 \times 10^{6}$ spermatozoa/ml (Adelia et al. 2017). Sperm was placed in a petri dish in the form of drops of $100 \mu$ for 10-20 oocytes and covered with mineral oil. (Sigma, USA). Each group of oocytes matured in the maturation medium supplemented with cysteamine $(0,50$, and $200 \mu \mathrm{m})$ were washed twice in the fertilization medium supplemented with $0.3 \%$ BSA and transferred to the spermatozoa drop, then were incubated in a $5 \% \mathrm{CO}_{2}$ in air at $38.5^{\circ} \mathrm{C}$ for 12 hours.

\subsection{Evaluation of In Vitro Fertilization Rate}

Fertilization rate was evaluated based on the pronuclear formation. Normal fertilization was characterized by the formation of two pronuclear (2 PN) after stained with $2 \%$ aceto orcein. Oocytes with more than two pronuclear are categorized as polyspermy.

\subsection{Statistical Analysis}

Data on nuclear maturation rate and fertilization rate were presented in percentage and statistically analyzed using Analysis of Variance (ANOVA). If any significant differences between treatments, data analysis was continued by the Duncan's Multiple Range Test (DMRT) (Steel and Torrie 1993). Analysis data was processed using the SPSS version 22.0 program. 


\section{Results}

Thepercentageof oocytes that reached the metaphase II (MII) stage with cysteamine supplementation in the maturation medium were control $(76.3 \pm 12.5), 50 \mu \mathrm{m}$ (86.5 \pm 8.6$), 100 \mu \mathrm{m}(85.0 \pm 7.5), 150 \mu \mathrm{m}(90.7 \pm 11.2)$, and $200 \mu \mathrm{m}(92.8 \pm 9.8)$, respectively. These results indicated that the cysteamine concentrations at $150 \mu \mathrm{m}$ and 200 $\mu \mathrm{m}$ were able to increase the nuclear maturation of oocyte $(\mathrm{MII})$ significantly higher $(\mathrm{p}<0.05)$ compared to the control (Table 1 ).

In the second experiment, the percentage of normal fertilization rate containing $50 \mu \mathrm{m}$ and $200 \mu \mathrm{m}$ of cysteamine were $(69.5 \pm 4.9)$ and $(71.0 \pm 9.2)$, respectively and statistically significant higher $(\mathrm{p}<0.05)$ than control (55.8 \pm 7.0$)$ (Table 2). Similarly, the percentage of the total fertilized rate in medium containing cysteamine $50 \mu \mathrm{m}$ and $200 \mu \mathrm{m}$ were (77.8 \pm 3.2$)$ and (85.0 \pm 7.3$)$, respectively and were significantly higher $(p<0.05)$ compared to the control $(65.8 \pm 1.4)$. The result indicates that the cysteamine supplementation in the maturation medium could increase the number of normal fertilization rate of sheep oocytes. Meanwhile, the percentage of polyspermy was not significantly differed $(p>0.05)$ between treatment and control (Table 2).

The success of in vitro fertilization is characterized by the formation of pronuclear (PN). In normal fertilization, there are two pronuclear (2PN) in the oocyte, whereas in polyspermy fertilization, there are more than two pronuclear in the oocyte as shown in Figure 1.

Table 1 . The nuclear maturation rate of the sheep oocyte by cysteamine supplementation in the IVM

\begin{tabular}{|c|c|c|c|c|c|c|}
\hline \multirow{2}{*}{ Cysteamine $(\mu \mathrm{m})$} & \multirow{2}{*}{ Number of Oocyte (n) } & \multicolumn{5}{|c|}{ Maturation Rate $\mathrm{n}(\% \pm \mathrm{SD})$} \\
\hline & & $\overline{\text { GVBD }}$ & MI & $\mathrm{A} / \mathrm{TI}$ & MII & DEG \\
\hline 0 & 91 & $3(2.8 \pm 5.2)$ & $14(17.5 \pm 10.1)^{\mathrm{a}}$ & $0(0.0 \pm 0.0)$ & $71(76.3 \pm 12.5)^{b}$ & $3(3.2 \pm 5.7)$ \\
\hline 50 & 92 & $0(0.0 \pm 0.0)$ & $12(13.5 \pm 8.6)^{a}$ & $0(0.0 \pm 0.0)$ & $80(86.5 \pm 8.6)^{a, b}$ & $0(0.0 \pm 0.0)$ \\
\hline 100 & 84 & $0(0.0 \pm 0.0)$ & $11(14.0 \pm 6.4)^{\mathrm{a}, \mathrm{b}}$ & $1(1.0 \pm 2.4)$ & $72(85.0 \pm 7.5)^{\mathrm{a}, \mathrm{b}}$ & $0(0.0 \pm 0.0)$ \\
\hline 150 & 85 & $2(1.8 \pm 2.9)$ & $7(6.7 \pm 8.4)^{\mathrm{a}, \mathrm{b}}$ & $1(0.8 \pm 2.0)$ & $75(90.7 \pm 11.2)^{a}$ & $0(0.0 \pm 0.0)$ \\
\hline 200 & 80 & $1(0.8 \pm 2.0)$ & $6(6.3 \pm 8.0)^{b}$ & $0(0.0 \pm 0.0)$ & $73(92.8 \pm 9.8)^{a}$ & $0(0.0 \pm 0.0)$ \\
\hline
\end{tabular}

Different superscripts in the same column showed a significant difference ( $\mathrm{p}<0.05)$. GVBD: germinal vesicle breakdown, MI: metaphase I, A/TI: anaphase/telophase I, MII: metaphase II, DEG: degeneration

Table 2. The fertilization rate of sheep oocytes by cysteamine supplementation in the IVM

\begin{tabular}{cclcc}
\hline \multirow{2}{*}{ Cysteamine $(\mu \mathrm{m})$} & \multirow{2}{*}{ Number of Oocyte $(\mathrm{n})$} & $\begin{array}{l}\text { Total of fertilized } \\
\mathrm{n}(\% \pm \mathrm{SD})\end{array}$ & \multicolumn{2}{c}{ Pronuclear Formation $\mathrm{n}(\% \pm \mathrm{SD})$} \\
\cline { 3 - 5 } & 87 & $57(65.8 \pm 2.9)^{\mathrm{b}}$ & Normal $(2 \mathrm{PN})$ & Polyspermy $(>2 \mathrm{PN})$ \\
\hline 0 & 80 & $62(77.8 \pm \pm 3.2)^{\mathrm{a}}$ & $55(69.5 \pm 7.0)^{\mathrm{b}}$ & $9(10.0 \pm 9.1)$ \\
200 & 81 & $69(85.0 \pm 7.3)^{\mathrm{a}}$ & $57(71.0 \pm 9.2)^{\mathrm{a}}$ & $7(8.5 \pm 3.7)$ \\
\hline
\end{tabular}

The mean in the same column with different superscripts showed a significant difference ( $<<0.05)$. 2PN: two pronuclear, $>2 \mathrm{PN}$ : more than two pronuclear

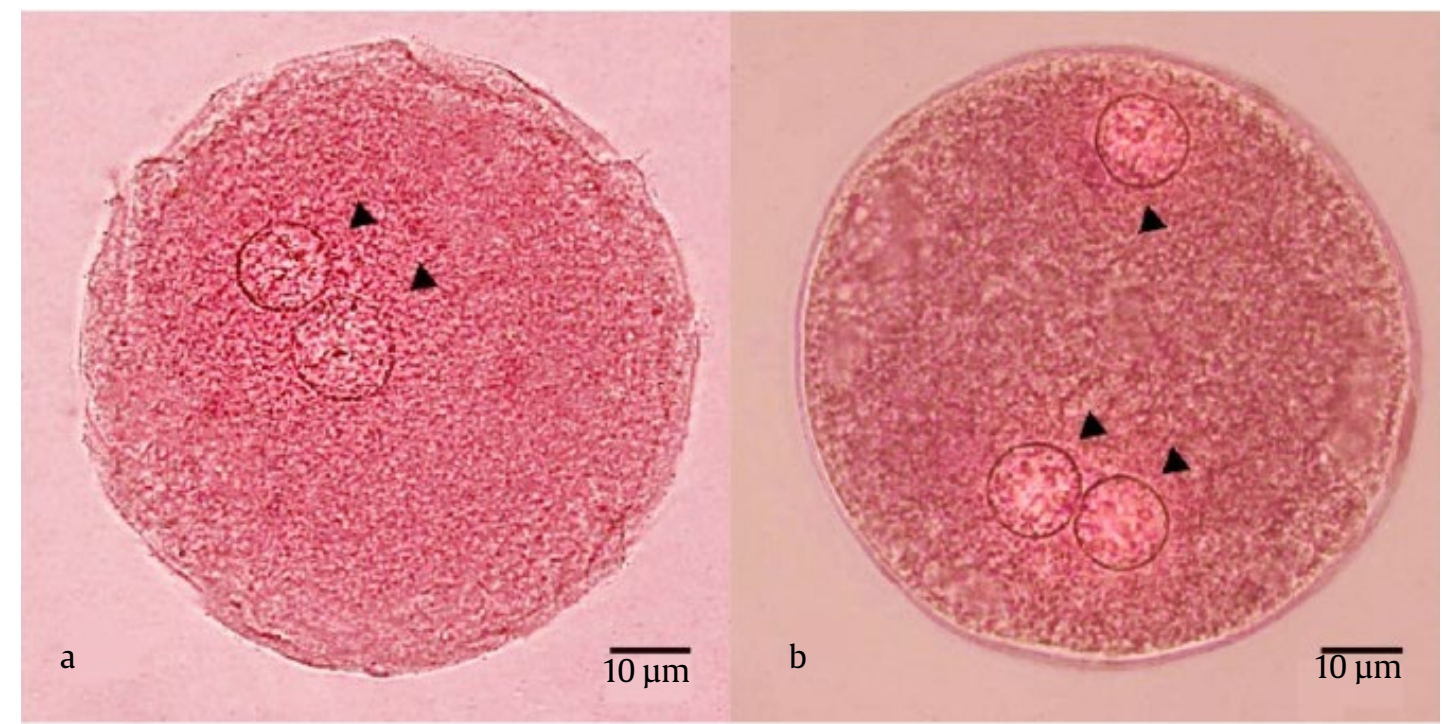

Figure 1. Formation of pronuclear in the oocyte after fertilization. (a) Two pronuclear, (b) More than two pronuclear. Images were taken using a phase- contrast microscope 


\section{Discussion}

In our study, cysteamine supplementation during maturation period in concentrations of $150 \mu \mathrm{m}$ and $200 \mu \mathrm{m}$ increased percentage of nuclear maturation of sheep oocyte. This indicated that cysteamine supplementation in IVM medium could increase GSH content in oocyte. However, the effect of addition cysteamine on GSH content was not evaluated in current study. Furthermore, according to Zhou et al. (2008) cysteamine supplementation was significantly increase GSH intracellular content with increasing concentrations of cysteamine up to $500 \mu \mathrm{m}$. It is well known that the culture systems increase ROS production since animal death started to culture process. The research by Tiwari and Chaube (2017) reported that in vitro culture systems could increase ROS levels in oocyte. A multitude of key factors regulate the generation of ROS in the media and include various cellular metabolic reactions, oxygen concentration, light, oocyte handling, and general physicochemical parameters that may have a negative impact on oocyte physiology by inducing apoptosis (Khazaei and Aghaz 2017).

In fact, oocytes have a defense mechanism to protects themselves from oxidative stress which could decrease oocyte competence. However, an imbalance of ROS production and the availability an antioxidant could induce cellular damage and even early embryo death rapidly. It is therefore many researchers added various antioxidants into the culture medium in order to reduce the harmful effects of ROS on IVEP, such as GSH (Triwulanningsih et al. 2002; Nugroho et al. 2017), green tea leaves extract (Barakat et al. 2014), and combination of Acetyl-L-Carnitine, N-Acetyl-LCysteine and $\alpha$-Lipoic Acid (Truong et al. 2016). The present study was done an effort to increase GSH content with cysteamine supplementation. GSH synthesis is affected by the availability of amino acid cysteine as a precursor (Lu 2013). Exogenous cysteine is very unstable and readily oxidizes to cystine, so that cysteine availability decrease rapidly and as consequence GSH concentration drastically decrease. These data were supported by research on cysteamine supplementation in the IVM medium which can increase the availability of cysteine and the concentration of GSH during the maturation process (De Matos et al. 1995; Gasparrini et al. 2003; Zhou et al. 2008).

GSH is synthesized in the cytosol part of the oocyte cytoplasm and then transported to cellular compartments such as the mitochondria, nucleus, and endoplasmic reticulum, where redox buffering is required for organelle-specific functions (Dominko and Dikic 2018; Jeong et al. 2018). Luberda (2005) reported that GSH plays an important role in oocyte function including protecting oocytes from the effects of ROS and controlling spindle thread morphology in the oocyte maturation process. These fact is proven by results of Roushandeh et al. (2008) that supplementation cysteamine in $200 \mu \mathrm{m}$ could improve spindle shape and size and increased GSH synthesis in mice oocyte. Another research conducted by An et al. (2018) revealed that cysteamine increases oocyte GSH concentration and improves gene expression for oocyte maturation, then could prevent oocyte apoptosis. In addition, Diaz-Vivancos et al. (2010) reported that GSH also regulates chromatin structure and chromatin condensation dynamics. Another mechanism showed by Garcia-Gimenez et al. (2013), who reported that GSH participates in numerous metabolic and cell signaling processes including protein synthesis and amino acid transport, DNA repair and the control of cell division and cell suicide program. Those process was believed in supporting better nuclear maturation mechanism.

To evaluate the ability oocyte to be fertilized, this study was done by observation of pronuclear formation. The concentration cysteamine used in this study were the lowest and the highest concentration from the research of oocyte maturation. Results of this study on fertilization rate, showed that at concentration of $50 \mu \mathrm{m}$ cysteamine could improve fertilization rate significantly compared to the control. Furthermore, our results justified that fertilization rate was better significantly higher in the oocyte supplemented by cysteamine compared to the control. These data indicated that cysteamine supplementation was presumable could increase GSH concentration either for protection from ROS or to improve fertilization rate. This is confirmed by Canel et al. (2018) that cysteamine supplementation during IVM, competent oocytes could increase their ability to synthesize GSH, facilitating the replacement of sperm protamins by histones during the male pronuclear formations. Although cysteamine in concentration 50 $\mu \mathrm{m}$ could not increase nuclear maturation, however it is presumable could increase oocyte quality, thus improve fertilization rate. These statement is supported by Sandal et al. (2018) that cysteamine can increase GSH content to protect the cell, as well as increasing cell quality. 
On the other hand, many research studies showed GSH content in oocyte plays an important role in the success of fertilization. The research on GSH supplementation in fertilization medium of bovine oocyte by Nugroho et al. (2017) reported that $1 \mathrm{~mm}$ GSH supplementation was more effective in supporting the normal pronuclear formation and early bovine embryonic development. The role of GSH on pronuclear formation was done by reducing disulfide bonds in the zona pellucida (ZP) of the oocyte and removal of sperm membranes, through the easier of oocyte cytoplasm (Takeo and Nakagata 2011). Furthermore, it was reported that GSH is requisite to ensure sperm chromatin decondensation and disulfide bonds reduction in the sperm nucleus and to promote of male pronuclear formation during fertilization (Yoshida et al. 1993; Sutovsky et al. 2000; Shirazi et al. 2018). Therefore, GSH synthesis during oocyte maturation is an important factor for promoting the ability of oocytes to form a male pronuclear.

Based on the results of this research, cysteamine supplementation in the IVM with concentrations of $150 \mu \mathrm{m}$ and $200 \mu \mathrm{m}$ were significantly improve the nuclear maturation of sheep oocyte. Even though supplementation of $50 \mu \mathrm{m}$ cysteamine in the IVM could not significantly improve nuclear maturation, but it was very effective to improve pronuclear formation in sheep oocyte.

\section{References}

Adelia $\mathrm{R}$ et al. 2017. Kafein dalam medium maturasi meningkatkan fertilisasi dan menekan frekuensi polispermi oosit domba dengan maturasi diperpanjang. J Vet 18:337-344.

An L et al. 2018. Synergistic effect of cysteamine, leukemia inhibitory factor, and Y27632 on goat oocyte maturation and embryo development in vitro. Theriogenology 108:56-62.

Arregui L et al. 2008. Xenografting of sheep testis tissue and isolated cells as a model for preservation of genetic material from endangered ungulates. Reproduction 136:85-93.

Barakat IAH et al. 2014. Antioxidant effect of green tea leaves extract on in vitro production of sheep embryos. Pak J Zool 46:167-175.

Canel NG et al. 2018. Improved embryo development using high cysteamine concentration during IVM and sperm co-culture with COCs previous to ICSI in bovine. Theriogenology 117:26-33.

De Matos DG, Furnus CC. 2000. The importance of having high glutathione (GSH) level after bovine in vitro maturation on embryo development: effect of $\beta$-mercaptoethanol, cysteine and cystine. Theriogenology 53:761-771.

De Matos DG et al. 1995. Effect of cysteamine on glutathione level and development capacity of bovine oocyte matured in vitro. Mol Reprod Dev 42:432-436.
Diaz-Vivancos P et al. 2010. A nuclear glutathione cycle within the cell cycle. Biochem J 431:169-178.

Dominko K, Dikic D. 2018. Glutathionylation: a regulatory role of glutathione in physiological processes. Arh Hig Rada Toksikol 69:1-24.

El-Aziz AHA et al. 2016. Factors influencing in vitro production of bovine embryos: a review. Asian J Anim Vet Adv 11:737-756.

Garcia-Gimenez et al. 2013. Nuclear glutathione. Biochim Biophys Acta 1830:3304-3316.

Gasparrini B et al. 2003. Glutathione synthesis during in vitro maturation of buffalo (Bubalus bubalis) oocytes: effects of cysteamine on embryo development. Theriogenology 60:943-952.

Hosseini SM et al. 2009. Antioxidant supplementation of culture medium during embryo development and/ or after vitrification-warming; which is the most important? J Assist Reprod Genet 26:355-364.

Jeong EM et al. 2018. Real-time monitoring of glutathione in living reveals that high glutathione levels are required to maintain stem cell function. Stem Cell Rep 10:600614.

Kang JT et al. 2016. Effect of antioxidant flavonoids (quercetin and taxifolin) on in vitro maturation of porcine oocytes. Asian Australas J Anim Sci 29:352-358.

Karasahin T, Arikan S. 2015. The effect of oleic and linoleic acids on in vitro bovine embryonic development and embryo quality. Turk J Vet Anim Sci 39:154-159.

Khazaei M, Aghaz F. 2017. Reactive oxygen species generation and use of antioxidants during in vitro maturation of oocytes. Int J Fertil Steril 11:63-70.

Lord T, Aitken RJ. 2013. Oxidative stress and ageing of the post-ovulatory oocyte. Reproduction 146:217-227.

Lu SC. 2013. Glutathione synthesis. Biochim Biophys Acta 1830:3143-3153.

Luberda Z. 2005. The role of glutathione in mammalian gametes. Reprod Biol 5:5-17.

[MENLHK] Menteri Lingkungan Hidup dan Kehutanan. 2018. Peraturan Menteri Lingkungan Hidup dan Kehutanan Republik Indonesia Nomor P.20/MENLHK/SETJEN/ KUM.1/6/2018 tentang Jenis Tumbuhan dan Satwa yang Dilindungi. Jakarta: Kementerian Lingkungan Hidup dan Kehutanan.

Nugroho AP et al. 2017. Penambahan glutathione pada medium fertilisasi efektif mendukung pembentukan pronukleus dan perkembangan awal embrio sapi. $J$ Vet 18:327-336.

Roushandeh et al. 2008. Presence of antioxidant in in vitro maturation medium and its effects on glutathione level, spindle area and rate of in vitro fertilization. Iran J Med Sci 33:37-43.

Sadeesh EM et al. 2014. Effect of growth factor and antioxidant on in vitro maturation of oocytes and cleavage rates of in vitro produced Indian buffalo (Bubalus bubalis) embryos. Vet Arhiv 84:459-474.

Sandal AI et al. 2018. In vitro maturation of bovine oocytes: beneficial effects of cysteamine. J Dairy Vet Anim Res 7:64-65.

Setiadi MA, Karja NWK. 2013. Tingkat perkembangan awal embrio sapi in vitro menggunakan media tunggal berbahan dasar tissue culture medium (TCM) 199. J Ked Hewan 7:150-154.

Shirazi A et al. 2018. Male pronuclear formation and embryo development following intracytoplasmic injection of ovine pretreated sperm. Avicenna J Med Biotechnol1:41-48.

Sovernigo TC et al. 2017. Effects of supplementation of medium with different antioxidants during in vitro maturation of bovine oocytes on subsequent embryo production. Reprod Dom Anim 52:561-569. 
Steel RGD, Torrie JH. 1993. Prinsip dan Prosedur Statistika: Suatu Pendekatan Biometrik. Jakarta: Gramedia Pustaka Utama.

Sutovsky P et al. 2000. Ubiquitinated sperm mitochondria, selective proteolysis, and the regulation of mitochondrial inheritance in mammalian embryos. Biol Reprod 68:582-590.

Suzuki K et al. 2000. Effect of hyaluronan on monospermic penetration of porcine oocytes fertilized in vitro. Int J Androl 23:13-21.

Takeo T, Nakagata N. 2011. Reduced glutathione enhances fertility of frozen/thawed C57BL/6 mouse sperm after exposure to methyl-beta-cyclodextrin. Biol Reprod 85:1066-1072.

Tiwari M, Chaube SK. 2017. Increase of reactive oxygen species associates with the achievement of meiotic competency in rat oocytes cultured in vitro. React Oxyg Species 4:320-335.
Triwulanningsih E et al. 2002. Penggunaan glutathione dalam medium fertilisasi guna meningkatkan persentase blastosis embrio sapi. JITV 7:116-123.

Truong TT et al. 2016. Antioxidants improve mouse preimplantation embryo development and viability. Hum Reprod 31:1445-1454.

Yoshida $\mathrm{M}$ et al. 1993. Glutathione concentration during maturation and after fertilization in pig oocytes: relevance to the ability of oocytes to form male pronucleus. Biol Reprod 49:89-94.

Zhou P et al. 2008. The interactions between cysteamine, cystine and cumulus cells increase the intracellular glutathione level and developmental capacity of goat cumulus-denuded oocytes. Reproduction 135:605611. 